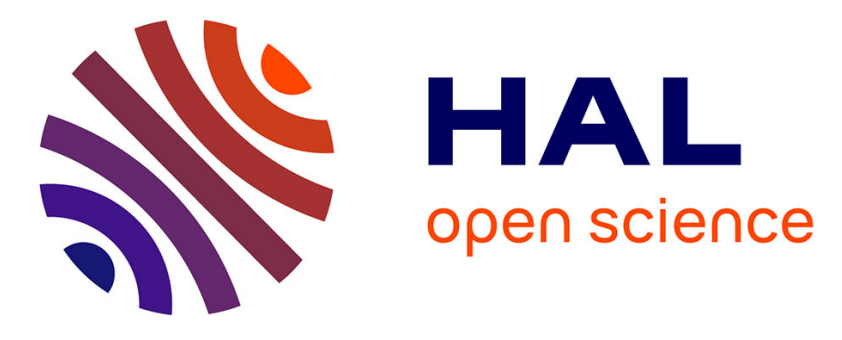

\title{
Experimental Study of the NIEL Scaling for Silicon Devices
}

Thierry Nuns, Christophe Inguimbert, Sabine Soonckindt, Ben Dryer, T. Buggey, C. Poivey

\section{- To cite this version:}

Thierry Nuns, Christophe Inguimbert, Sabine Soonckindt, Ben Dryer, T. Buggey, et al.. Experimental Study of the NIEL Scaling for Silicon Devices. RADECS 2018, Sep 2018, GOTEBORG, Sweden. hal01957210

\author{
HAL Id: hal-01957210 \\ https://hal.science/hal-01957210
}

Submitted on 17 Dec 2018

HAL is a multi-disciplinary open access archive for the deposit and dissemination of scientific research documents, whether they are published or not. The documents may come from teaching and research institutions in France or abroad, or from public or private research centers.
L'archive ouverte pluridisciplinaire HAL, est destinée au dépôt et à la diffusion de documents scientifiques de niveau recherche, publiés ou non, émanant des établissements d'enseignement et de recherche français ou étrangers, des laboratoires publics ou privés. 


\title{
Experimental Study of the NIEL Scaling for Silicon Devices
}

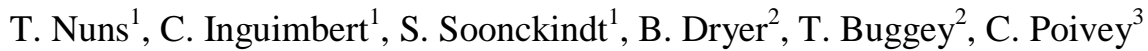

\begin{abstract}
This paper proposes some new experimental data comparing the damage factor of silicon devices with the NIEL after electron, proton and gamma irradiations. The results show that the measured damage factors fit better with the "effective" NIEL, an alternative model of displacement damage effects, than with the classical one.
\end{abstract}

Index Terms - Space Environment, Displacement Damage, Non-Ionizing Energy Loss

\section{INTRODUCTION}

$\mathrm{T}$ he Non-Ionizing Energy Loss (NIEL) [1]-[5] scaling factor has been used for some decades for the evaluation of displacement damage dose received by electronic devices for space application. This parameter is equivalent to the Linear Energy Transfer (LET) for ionizing effects. The displacement damage dose (DDD) at the device level during a mission is given by the following equation:

$$
D D D=\int_{E_{\min }}^{E_{\max }} N I E L(E) \Phi(E) d E(1)
$$

Where $E_{\min }$ and $E_{\max }$ are the minimum and maximum energies of the spectrum, $\Phi(\mathrm{E})$ is the differential fluence of the mission at the energy $\mathrm{E}$ at the device level.

On the other hand, many studies are related to the evolution of the electrical parameters after irradiation due to displacement damage for a given particle type and energy. Some are directly related to the evolution of physical parameters, like the thermal generation rate $\mathrm{G}$ or the minority carrier diffusion length $\mathrm{L}$. In particular, the increase of $\mathrm{G}$ [6] and $1 / \mathrm{L}^{2}[7]$ are shown to be directly proportional to the fluence. The coefficient between the increase of these parameters and the fluence is the damage factor $\left(\mathrm{K}_{\mathrm{G}}\right.$ or $\mathrm{K}_{\mathrm{L}}$ in our case), which is shown to be proportional to the NIEL [6][8]-[10]. This statement is very interesting for space projects because it implies proportionality between the DDD and the degradation whatever the particle type and energy. However, some deviations in the NIEL scaling were observed with electrons both for $\mathrm{Si}$ and GaAs [11]-[21]. Some

(1) T. Nuns, C. Inguimbert, T. Nuns and S. Soonckindt are with ONERADPHY, 2 avenue E. Belin, 31055 Toulouse, France (email: thierry.nuns@onera.fr).

(2) B. Dryer and T. Buggey are with The Open University CEI, Walton Hall, Milton Keynes, MK7 6AA, United Kingdom (email: mailto:ben.dryer@open.ac.uk).

(3) C. Poivey is with the ESA-ESTEC (TEC-QEC), European Space Agency, Keplerlaan 1, P.O. Box 299, 2200 AG Noordwijk ZH, The Netherlands (email: mailto:ben.dryer@open.ac.uk). interpretations have been given in the past to explain the discrepancies observed in the case of electrons and gamma rays [23]-[27] where the relationship between damage factors and the low NIEL values is shown to be sometimes quadratic. In particular, the work of Inguimbert and al. [24] proposes refined calculations of the "effective" NIEL using the results of molecular dynamics simulations. They show that the classical NIEL calculation may be overestimated and that the use of the "effective" NIEL calculation may better predict displacement damage effects for low energy electrons.

The aim of this work is to provide new experimental evaluations of damage factors on silicon devices and to use them to compare the "effective" and "classical" NIEL calculation methods. We also provide some calculations of the NIEL of gamma of a ${ }^{60} \mathrm{Co}$ source using the effective NIEL with the same hypothesis presented in [22], except that they are analytic instead of Monte Carlo calculations. The devices are silicon imagers and photodiodes that are irradiated with protons in the range 6.5-200 $\mathrm{MeV}$, electrons in the range 0.3 $20 \mathrm{MeV}$ and ${ }^{60} \mathrm{Co}$ gamma rays. The measurements focus on the thermal generation via the measurement of the dark current for a large part of the irradiations and device types. For the low energy electrons (below $1 \mathrm{MeV}$ ) where the total ionizing dose effects could be a problem, some specific experiments aim at the evaluation of the diffusion length by the measurement of the short circuit current measured on the photodiodes during irradiation.

\section{EXPERIMENTAL SETUP}

\section{A. Devices in study}

Four device types were used for this study. Two of them are imagers and two are photodiodes. The first imager is a CMOS Image Sensor (CIS) Teledyne E2V EV76C560 Sapphire with 1.3 Mpixels $(1,024 \times 1,280)$. The pixel pitch is $5.3 \mu \mathrm{m}$ square. For the measurements at four temperatures $(15,21,27$ and $35^{\circ} \mathrm{C}$ ), the device is operated in rolling shutter mode with true correlated double sampling. The A/D conversion is made by an on-chip 10-bit ADC. The samples irradiated in this study are all from the same lot.

The second imager is the charge coupled device Teledyne E2V CCD47-20, an advanced inverted mode $1024 \times 1024$ pixel full-frame device with a pixel pitch of $13.3 \mu \mathrm{m}$ square. A store region allows the readout of the previous frame while the subsequent image is integrating. The device is split and readout through two outputs referenced as node 1 and node 2 . The measurements at 6 temperatures $(-30,-20,-10,0,10$, $15^{\circ} \mathrm{C}$ ) are made in CDS mode with an external ADC. The low 
readout time imposes some long integration times and thus small operating temperatures. The analysis focusses on the pixel dark current generation rate.

The first diode is a CANBERRA FD50-14-300RM Passivated Implanted Planar Silicon (PIPS) detector. It is a $\mathrm{P}^{+} \mathrm{N}$ silicon diode with a $\mathrm{P}^{+}$implanted layer. The $\mathrm{N}$-type silicon resistivity is close to $8000 \Omega . \mathrm{cm}$. Lateral borders are passivated. The circular active area is $50 \mathrm{~mm}^{2}$ and the fully depleted thickness is $300 \mu \mathrm{m}$. The reverse $\mathrm{I}(\mathrm{V})$ in the dark are obtained at $15,21,27$ and $35^{\circ} \mathrm{C}$. Measurements of the short-circuit current are performed at approximately room temperature.

The second photodiode is the Hamamatsu S1337-33BQ, which has a square active area of $2.4 \times 2.4 \mathrm{~mm}$ with a depletion thickness on the order of $5 \mu \mathrm{m}$. We only present measurements of the short-circuit current at approximately room temperature on this device. All the photodiode samples of the same reference are from the same lot.

\section{B. Measurements}

The CIS Saphirre and CCD 47-20 imagers are operated by dedicated test benches (ONERA and Open University respectively) that ensure the electrical measurements and the thermal regulation. The electrical measurements consist in picture captures with various integration times. The photodiodes are measured by ONERA on a Keithley 4200SCS test bench with SMUs and preamplifiers that allow the measurement of very low levels of currents (below $100 \mathrm{pA}$ ). The samples are thermally regulated with accuracy close to $0.1^{\circ} \mathrm{C}$.

For the imagers, we focus here on the mean dark current. The homogeneity of the degradation over the irradiated area have been checked. In the case of the CIS Saphirre, we also measured the conversion factor thanks to the KTC noise [28]. Indeed, the output signal is a digital value in lsb. If the charge to lsb ratio changes because of the irradiation, the dark current measurements must be corrected.

The damage factor is calculated by dividing the dark current increase by the fluence for both Canberra PIPS diodes and the imagers. The majority of the thermal annealing processes are believed to have taken place in the first few days following irradiation. In order to take them into account and to get the "final state" of the displacement damage, all the measurements are made one month after irradiation.

For the low energy $(0.3,1.3 \mathrm{MeV})$ electron irradiations, we measure the short-circuit current $\mathrm{I}_{\mathrm{sc}}$ of the device produced by the irradiation electron flux in the dark. The variation of the current is directly proportional to the flux. Calibrations at $800 \mathrm{keV}$ over two decades of flux (some $10^{9}$ to some $10^{11} \mathrm{e}^{-}$ $/ \mathrm{cm}^{2} / \mathrm{s}$ ) give a quasi-linear fit (exponential factor of 1.14 and 1.06 for the Canberra and Hamamatsu photodiodes respectively). This method is presented in [29]. For a given flux, because $I_{\mathrm{sc}}$ is proportional to the diffusion length, the variation of $1 / \mathrm{I}_{\mathrm{sc}}{ }^{2}$ is proportional to the fluence. We can then extract a damage factor from the variation of $1 / \mathrm{I}_{\mathrm{sc}}{ }^{2}$ which is related to $1 / \mathrm{L}^{2}$. This factor is device specific.

\section{Irradiations}

The proton irradiations were performed at the STERIS facility in Harwell UK under vacuum for $6.5 \mathrm{MeV}$ and at the Paul Scherrer Institute in air for the other proton energies. All proton energies but $17.25 \mathrm{MeV}$ are primary particle energies, with the $17.25 \mathrm{MeV}$ protons generated through degradation of a $72.8 \mathrm{MeV}$ particle beam with copper degraders. The high energy electron irradiations ( 6 to $20 \mathrm{MeV}$ ) were performed at the RADEF facility of the University of Jyväskylä (FI) in air. The low electron energies irradiations were performed at the GEODUR facility of ONERA (FR) under vacuum. Finally, the gamma irradiations were performed at the MEGA facility of ONERA with a ${ }^{60} \mathrm{Co}$ source at a dose rate of $20 \mathrm{~Gy}(\mathrm{Si}) / \mathrm{h}$. The devices are irradiated at normal incidence with cover glass removed, unbiased and in the dark. For the CCD47-20, the proton and $1 \mathrm{MeV}$ electron irradiations were performed with steel shielding covering a large part of the device except for a rectangular window such that only a part of the pixel array is irradiated. The thickness of the shielding is $15 \mathrm{~mm}$ for $1 \mathrm{MeV}$ electrons, 6.5 and $72.8 \mathrm{MeV}$ protons and $60 \mathrm{~mm}$ for $200 \mathrm{MeV}$ protons. In this case, the actual nominal size of the region of interest is 230 columns by 830 rows (240,700 pixels). Because of the high electron flux at GEODUR (vacuum) during the measurement of the short circuit current (see TABLE II), the diodes are put on a thermal plate that ensures that the devices will not heat during irradiation. TABLE I and TABLE II give the details of the energies, fluences and ionizing dose experienced by each device. TABLE I concerns the measurements of dark current on the devices while TABLE II deals with the measurements of the short-circuit current during irradiation.

TABLE I: PROTON, ELECTRON AND GAMMA IRRADIATIONS OF THE IMAGERS AND PIPS

\begin{tabular}{|c|c|c|c|}
\hline $\begin{array}{l}\text { Particle } \\
\text { Species }\end{array}$ & Energy $(\mathrm{MeV})$ & $\mathrm{CCD}$ & $\begin{array}{c}\text { Photodiodes PIPS } \\
\text { Canberra } \\
\end{array}$ \\
\hline \multirow{3}{*}{ Protons } & $\begin{array}{l}6.5 \text { (CIS and } \\
\text { CCD) or } 17.25 \\
\text { (photodiodes) }\end{array}$ & $\begin{array}{c}30 \mathrm{~Gy}(\mathrm{Si}) \\
\left(3.8910^{9} \mathrm{p}^{+} / \mathrm{cm}^{2}\right)\end{array}$ & $\begin{array}{c}15 \mathrm{~Gy}(\mathrm{Si}) \text { and } 30 \mathrm{~Gy}(\mathrm{Si}) \\
\left(4.1110^{9} \mathrm{p}^{+} / \mathrm{cm}^{2} \text { and }\right. \\
\left.8.2210^{9} \mathrm{p}^{+} / \mathrm{cm}^{2}\right)\end{array}$ \\
\hline & 72.8 & $\begin{array}{c}30 \mathrm{~Gy}(\mathrm{Si}) \\
\left(2.5210^{10} \mathrm{p}^{+} / \mathrm{cm}^{2}\right)\end{array}$ & $\begin{array}{c}15 \mathrm{~Gy}(\mathrm{Si}) \text { and } 30 \mathrm{~Gy}(\mathrm{Si}) \\
\left(1.2610^{10} \mathrm{p}^{+} / \mathrm{cm}^{2} \text { and }\right. \\
\left.2.5210^{10} \mathrm{p}^{+} / \mathrm{cm}^{2}\right) \\
\end{array}$ \\
\hline & 200 & $\begin{array}{c}30 \mathrm{~Gy}(\mathrm{Si}) \\
\left(5.1610^{10} \mathrm{p}^{+} / \mathrm{cm}^{2}\right)\end{array}$ & $\begin{array}{c}15 \mathrm{~Gy}(\mathrm{Si}) \text { and } 30 \mathrm{~Gy}(\mathrm{Si}) \\
\left(2.5810^{10} \mathrm{p}+/ \mathrm{cm}^{2} \text { and }\right. \\
\left.5.1610^{10} \mathrm{p}+/ \mathrm{cm}^{2}\right)\end{array}$ \\
\hline \multirow{4}{*}{ Electrons } & 1 & $\begin{array}{c}100 \mathrm{~Gy}(\mathrm{Si}) \\
\left(4.0810^{11} \mathrm{e}^{-/ \mathrm{cm}^{2}}\right)\end{array}$ & $\begin{array}{c}50 \mathrm{~Gy}(\mathrm{Si}) \text { and } 100 \mathrm{~Gy}(\mathrm{Si}) \\
\left(2.0410^{11} \mathrm{e}^{-} / \mathrm{cm}^{2} \text { and }\right. \\
\left.4.0810^{11} \mathrm{e}^{-} / \mathrm{cm}^{2}\right)\end{array}$ \\
\hline & 6 & $\begin{array}{c}100 \mathrm{~Gy}(\mathrm{Si}) \\
\left(3.4510^{11} \mathrm{e}^{-/ \mathrm{cm}^{2}}\right)\end{array}$ & $\begin{array}{c}50 \mathrm{~Gy}(\mathrm{Si}) \text { and } 100 \mathrm{~Gy}(\mathrm{Si}) \\
\left(1.7210^{11} \mathrm{e}^{-} / \mathrm{cm}^{2} \text { and }\right. \\
\left.3.4510^{11} \mathrm{e}^{-} / \mathrm{cm}^{2}\right)\end{array}$ \\
\hline & 12 & $\begin{array}{c}100 \mathrm{~Gy}(\mathrm{Si}) \\
\left(2.9710^{11} \mathrm{e}^{-/ \mathrm{cm}^{2}}\right)\end{array}$ & $\begin{array}{c}50 \mathrm{~Gy}(\mathrm{Si}) \text { and } 100 \mathrm{~Gy}(\mathrm{Si}) \\
\left(1.4810^{11} \mathrm{e}^{-} / \mathrm{cm}^{2} \text { and }\right. \\
\left.2.9710^{11} \mathrm{e}^{-} / \mathrm{cm}^{2}\right)\end{array}$ \\
\hline & 20 & $\begin{array}{c}100 \mathrm{~Gy}(\mathrm{Si}) \\
\left(2.5310^{11} \mathrm{e}^{-/ \mathrm{cm}^{2}}\right)\end{array}$ & $\begin{array}{c}50 \mathrm{~Gy}(\mathrm{Si}) \text { and } 100 \mathrm{~Gy}(\mathrm{Si}) \\
\left(1.2610^{11} \mathrm{e}^{-} / \mathrm{cm}^{2} \text { and }\right. \\
\left.2.5310^{11} \mathrm{e}^{-} / \mathrm{cm}^{2}\right)\end{array}$ \\
\hline${ }^{60} \mathrm{Co}$ & 1.17 and 1.33 & $\begin{array}{c}30 \mathrm{~Gy}(\mathrm{Si}) \text { and } \\
100 \mathrm{~Gy}(\mathrm{Si})\end{array}$ & $\begin{array}{c}15 \mathrm{~Gy}(\mathrm{Si}), 30 \mathrm{~Gy}(\mathrm{Si}) \\
50 \mathrm{~Gy}(\mathrm{Si}) \text { and } 100 \mathrm{~Gy}(\mathrm{Si})\end{array}$ \\
\hline
\end{tabular}

As can be seen in TABLE I, the same ionizing dose is applied to the devices at the different energies. The goal is to normalize the ionizing dose effects on the devices as much as possible, even if we must keep in mind that the protons, electron and gamma rays have a different yield and the irradiation experience different dose rates that may induce a 
different level of electrical degradation. One device is irradiated per energy, except for the PIPS photodiodes where the devices are subjected to two fluence levels.

TABLE II: LOW ENERGY ELECTRON IRRADIATIONS FOR THE MEASUREMENT OF THE SHORT CIRCUIT CURRENT OF THE PHOTODIODES

\begin{tabular}{|c|c|c|c|c|c|}
\hline Diode & SN & $\begin{array}{c}\text { Energy } \\
(\mathrm{MeV})\end{array}$ & $\begin{array}{c}\text { Fluence } \\
\left(\mathrm{e}^{-} / \mathrm{cm}^{2}\right)\end{array}$ & $\begin{array}{c}\text { Flux } \\
\left(\mathrm{e}^{-} / \mathrm{cm}^{2} / \mathrm{s}\right)\end{array}$ & $\begin{array}{c}\text { Ionizing } \\
\text { dose } \\
(\mathrm{Gy}(\mathrm{Si}))\end{array}$ \\
\hline \multirow{4}{*}{$\begin{array}{c}\text { Hamamatsu } \\
\text { S1337- } \\
\text { BQ33 }\end{array}$} & 1 & 0.8 & $1.28 \times 10^{14}$ & $2.5 \times 10^{10}$ & $3.17 \times 10^{4}$ \\
\cline { 2 - 6 } & 2 & 0.5 & $1.28 \times 10^{14}$ & $2.5 \times 10^{10}$ & $3.38 \times 10^{4}$ \\
\cline { 2 - 6 } & 3 & 0.4 & $1.12 \times 10^{14}$ & $5.5 \times 10^{10}$ & $3.12 \times 10^{4}$ \\
\cline { 2 - 6 } & 4 & 0.35 & $1.09 \times 10^{14}$ & $5.0 \times 10^{10}$ & $3.15 \times 10^{4}$ \\
\cline { 2 - 6 } & 5 & 0.3 & $1.02 \times 10^{14}$ & $6.1 \times 10^{10}$ & $3.11 \times 10^{4}$ \\
\cline { 2 - 6 } & 6 & 0.3 & $1.02 \times 10^{14}$ & $5.0 \times 10^{10}$ & $3.11 \times 10^{4}$ \\
\cline { 2 - 6 } & 8 & 1.3 & $1.28 \times 10^{14}$ & $5.0 \times 10^{10}$ & $3.14 \times 10^{4}$ \\
\hline \multirow{2}{*}{$\begin{array}{c}\text { Canberra } \\
\text { FD00RM }\end{array}$} & 2 & 0.8 & $1.33 \times 10^{14}$ & $5.0 \times 10^{10}$ & $3.30 \times 10^{4}$ \\
\cline { 2 - 6 } & 3 & 0.5 & $1.23 \times 10^{14}$ & $2.9 \times 10^{10}$ & $3.25 \times 10^{4}$ \\
& 6 & 1.3 & $1.28 \times 10^{14}$ & $5.0 \times 10^{10}$ & $3.14 \times 10^{4}$ \\
\cline { 2 - 6 } & & & & &
\end{tabular}

\section{NIEL OF ${ }^{60} \mathrm{CO}$}

Gamma rays of a ${ }^{60} \mathrm{Co}$ source are able to produce atomic displacements by means of secondary electron production, [7] [16][21][30][31]. For instance, ${ }^{60} \mathrm{Co}$ gamma rays, having an average energy of $1.25 \mathrm{MeV}$, produce, by means of photoelectric absorption, Compton scattering and pair production, a spectrum of secondary electrons in the $[\mathrm{keV}$, $\mathrm{MeV}]$ range. It has been reported that the displacement damage effects caused by ${ }^{60} \mathrm{Co}$ gamma ray irradiation can be correlated with the effect of $1 \mathrm{MeV}$ electrons [7][30][31]. In this paragraph, we propose an alternative calculation than the one proposed in [22]. It consists in an analytical method instead of a Monte Carlo one. We compare the results at the end.

The gamma photons are able to produce in indirect way some atomic displacements in target materials, simply by producing secondary electrons which in turn are capable to displace atoms by means of coulombic interactions. The energetic photons of some $\mathrm{MeV}$, such as those produced by ${ }^{60} \mathrm{Co}$ radioactive sources, interact with the electrons of the matter by means of photoelectric effect, Compton scattering processes or pair productions. Between $100 \mathrm{keV}$ and up to some $\mathrm{MeV}$, the Compton scattering is the dominant process. In this energy range, we can neglect the other processes that are less probable and that mostly produce, like photoelectric effect, only low energetic electrons not capable to produce atomic displacements (Fig. 1).

For incident gamma rays, it is possible to evaluate the Compton electrons spectrum, and estimating the number of produced atomic displacements and thus at the end an equivalent NIEL for gamma rays. The equilibrium secondary electron spectrum must take into account the shielding surrounding the device. The production of secondary electrons is dominated by the shielding materials that are crossed by the gamma rays before impinging the device. This mechanism has been described by Summers et al. [16] and [21]. The NIEL of gamma rays have been calculated according to the method described in these references. This is briefly reminded here.

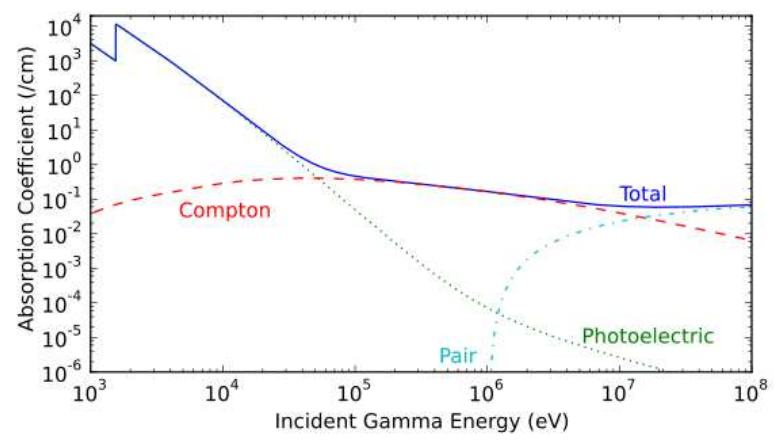

Fig. 1: Gamma rays absorption coefficient for aluminum target. The relative contributions of photoelectric, Compton and pair production effect are compared in the energy range $[100 \mathrm{keV}, 10 \mathrm{MeV}]$ the Compton scattering process dominates.

Let's focus on gamma rays produced by a ${ }^{60} \mathrm{Co}$ radioactive source. This radioactive material produces at each disintegration two photons of respectively $1.33 \mathrm{MeV}$ and $1.17 \mathrm{MeV}$. For the calculation we will use an average energy of 1.2 MeV. Let's then assume an aluminium slab shielding irradiated with a $1.2 \mathrm{MeV}$ photon source. The parallelepipedic shielding is sliced in elementary elements in which the Compton spectrum is quantified. Then, the spectrum of each slice is transported through the rest of the shielding down to the electronic component. The slowed down spectrum that irradiates the device is just the sum of all the transported spectra. The Compton electrons spectra can be calculated according to the Klein Nishina cross section formula:

$$
\begin{gathered}
\frac{d \sigma_{c}}{d \Omega}=\frac{r_{e}^{2}}{2}\left(\frac{1}{1+\frac{E_{\gamma}}{m_{e} c^{2}}(1-\cos (\theta))}\right)^{2} \cdot\left(\frac{1}{1+\frac{E_{\gamma}}{m_{e} c^{2}}(1-\cos (\theta))}+1+\frac{E_{\gamma}}{m_{e} c^{2}}(1-\cos (\theta))-1+\cos ^{2}(\theta)\right)^{(2)} \\
E_{\gamma}^{\prime}=E_{\gamma}\left(\frac{1}{1+E_{\gamma}(1-\cos (\theta))}\right)
\end{gathered}
$$

With $\mathrm{r}_{\mathrm{e}}^{2} \sim 7.940610^{-30} \mathrm{~m}^{2}$ and $\mathrm{m}_{\mathrm{e}} \mathrm{c}^{2}=0.511 \mathrm{MeV}$. The total cross section calculated according to the Klein Nishina formula is plotted as a function of incident photon energy inFig. 2.

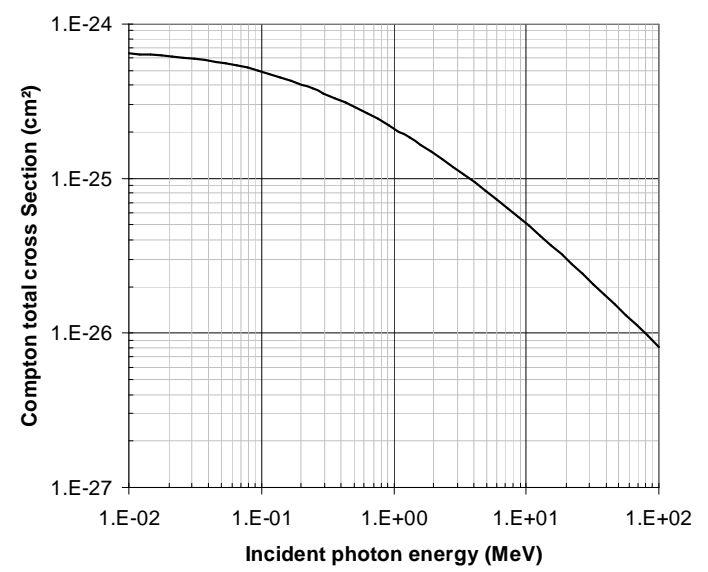

Fig. 2: Gamma rays Compton total cross section as a function of incident photon energy. 
At $1 \mathrm{MeV}$ the cross section is in the order of $0.2 \mathrm{mBarn}$. A first order estimate of the amount of produced secondary electrons can be calculated. An incident gamma photon of 1 $\mathrm{MeV}$ can produce only secondary electrons with energies lower than $1 \mathrm{MeV}$. The Compton electron produced in a shielding by incident $1 \mathrm{MeV}$ gamma rays can get out from the volume to reach the electronic device only if it is produced not to deeply in the shielding. Typically, at a depth lower than the practical range of $1 \mathrm{MeV}$ electrons $(\sim 1.5 \mathrm{~mm}$ in Aluminium). It means that in a $\sim 1 \mathrm{~mm}$ thickness target of aluminium, an incident gamma of $1 \mathrm{MeV}$ will produce in average $\sim 0.210^{-24}$ $\left(\mathrm{cm}^{2}\right) \times 610^{+22}$ × $13\left(\mathrm{~cm}^{-3}\right)$ x $0.1(\mathrm{~cm})=1.5610^{-2}$ Compton electrons. That means that $\sim 60$ incident gamma rays of $1 \mathrm{MeV}$ will produce in average a single secondary electrons. If we assume that this electron has an energy of $1 \mathrm{MeV}$ $\left(\mathrm{NIEL}_{\mathrm{Si}}=310^{-5} \mathrm{MeV} / \mathrm{g} \cdot \mathrm{cm}^{2}\right)$, we find a NIEL value of around $4.6810^{-7} \mathrm{MeV} / \mathrm{g} . \mathrm{cm}^{2}$ in Silicon. In reality even if secondary Compton electrons have energies most of time close to $1 \mathrm{MeV}$, the energy of secondaries are spread from some keV up to $1 \mathrm{MeV}$ as depicted by the Fig. 3. And that, without taking into account the slowing down of the initial Compton spectrum. That means that a more accurate calculation will lead to a lower gamma NIEL value in Silicon. At this stage this value is already two order of magnitude lower than the one $\left(1.30810^{-5} \mathrm{MeV} / \mathrm{g} . \mathrm{cm}^{2}\right)$ provided in the reference [16] and used by Srour [32].

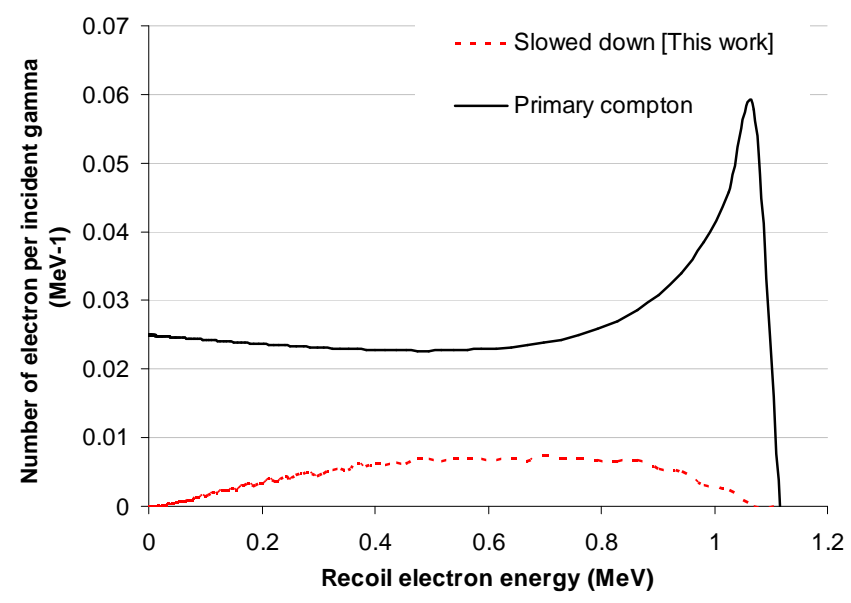

Fig. 3: Primary and slowed down Compton electron spectra for $1.33 \mathrm{MeV}$ incident gammas in aluminium.

The NIEL of gamma rays can be estimated accurately as the average NIEL of secondary Compton electrons capable to cross the shielding and reach the material of interest:

$$
N I E L_{\gamma}=\int_{0}^{E_{\max }} \frac{d S_{c}}{d Q}(Q) \cdot N I E L_{e}(Q) \cdot d Q^{(4)}
$$

Where $S_{c}$ is the slowed down spectrum that integrates both the production rate of secondary electrons and their transmission rate through the shielding (Fig. 3).

Eventually, for a Silicon target the calculation lead to a gamma NIEL of:

$$
\mathrm{NIEL}_{\mathrm{Si}, \gamma}=1.1210^{-7} \mathrm{MeV} / \mathrm{g} \cdot \mathrm{cm}^{2}
$$

That is fifty times lower than the value of the reference [16] $\left(1.3110^{-5} \mathrm{MeV} / \mathrm{g} \cdot \mathrm{cm}^{2}\right)$. But, the use of the effective NIEL model for electrons lead to a NIEL value for gamma rays even lower:

$$
\mathrm{NIEL}_{\text {eff }, \mathrm{Si}, \gamma}=5.110^{-9} \mathrm{MeV} / \mathrm{g} . \mathrm{cm}^{2}
$$

These results are very close to the data found in [22].

\section{EXPERIMENTAL RESULTS}

\section{A. CIS Saphirre}

The Fig. 4 shows the variation of the conversion factor of the CIS Saphirre after the various irradiations. There is a slight decrease which seems to depend on the total ionization dose. The maximum variation is obtained for the $6 \mathrm{MeV}$ electron irradiation $(10 \mathrm{~Gy}(\mathrm{Si}))$ with a decrease of almost $4.5 \%$. Because the variation is quite small, it was not corrected in the calculation of the dark current increase, neither in the damage factor. The absolute value of the conversion factor is close to $18 \mathrm{e}^{-/} / \mathrm{lsb}$.

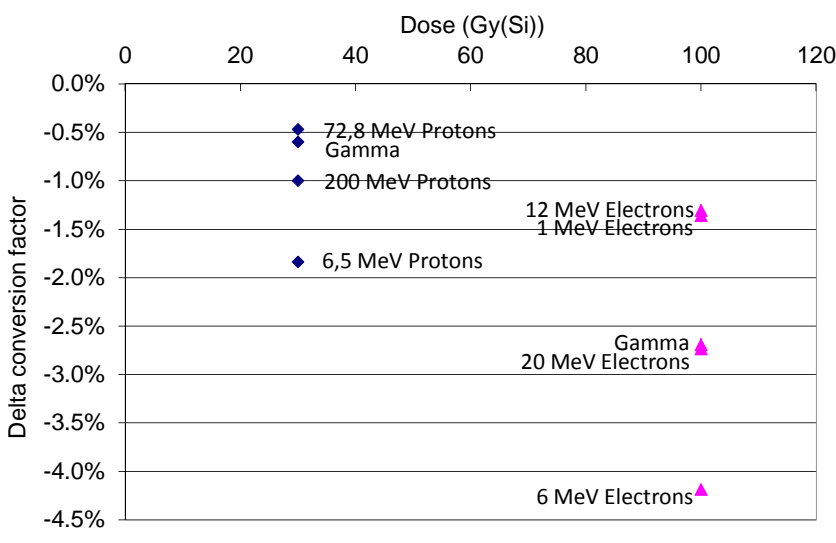

Fig. 4: Variation of the conversion factor of the CIS Saphirre after irradiation as a function of the total ionising dose.

Fig. 5 shows the CIS Sapphire dark current and dark current increase after the different irradiations at $27^{\circ} \mathrm{C}$. These results are the mean value of the dark current of the pixels over the ROI (a region of $724 \times 980$ pixels in the center of the array). The results at the other measurement temperature are quite the same in term of shape. Fig. 6 shows the corresponding damage factors, that are deduced by dividing the dark current (or dark current increase) by the fluence.

For proton irradiation, we can see the effect of increasing incident particle energy on the damage factor (Fig. 6), which changes in the same ratio as the NIEL. On the contrary, the damage factor is found to be very slightly increasing with incident electron energy. Even if the NIEL increases with the electron energy, this result is not consistent with the absolute NIEL variation. This is due to the high sensitivity of the dark current to ionizing effects at $100 \mathrm{~Gy}(\mathrm{Si})$ compared to the expected displacement damage effect of electrons. This was confirmed by the gamma irradiations where the dark current increase is higher than for electrons (which could be due to a different yield in the initial recombination of electron-hole pairs), as shown in Fig. 5. Note that the gamma damage factor is lower than electron ones because the gamma fluence is 
much higher for the same ionizing dose, even if the dark current increase is almost the same.

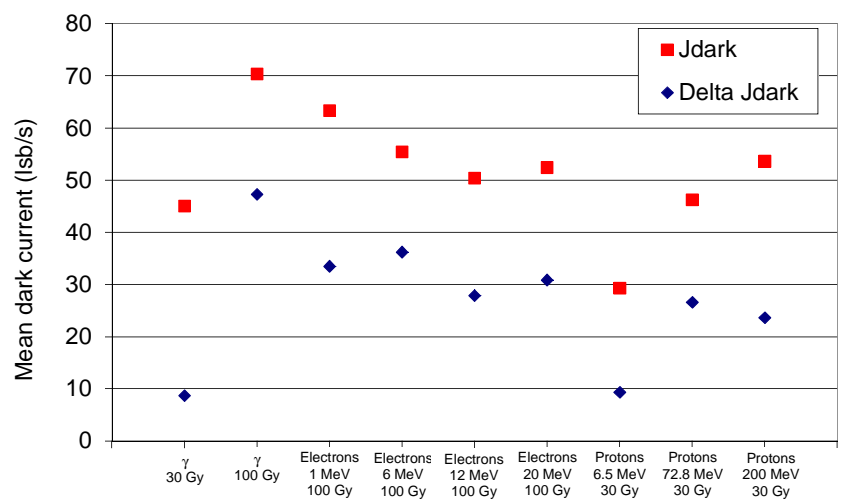

Fig. 5: CIS Sapphire dark current and mean dark current increase after irradiation at $27^{\circ} \mathrm{C}$.

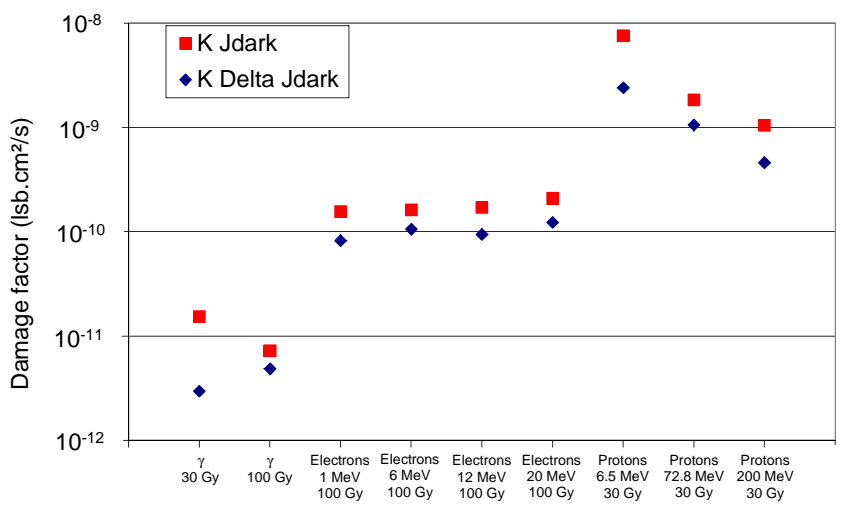

Fig. 6: CIS Sapphire damage factor of the mean dark current and mean dark current increase after irradiation at $27^{\circ} \mathrm{C}$.

\section{B. $C C D 47-20$}

The conversion factor of the CCD 47-20 did not show any significant change.

Fig. 7 shows the CCD 47-20 mean dark current and Fig. 8 the corresponding damage factor at $-10^{\circ} \mathrm{C}$. Measurements at lower temperatures like $-20^{\circ} \mathrm{C}$ are similar. The low operating temperatures provide the easiest interpretation of the results. Indeed, the highest temperatures may induce the saturation of some pixels. These results are the mean value of the dark current of the pixels over the ROI, centered on the nonshielded area during the irradiations (especially for protons and $1 \mathrm{MeV}$ electrons).

Because this device operates in an inverted mode, the ionizing effects are small compared to displacement damage ones even for electron irradiations as the photodiode is isolated from the surface defects created due to ionization. It is then possible to distinguish the effects of the electron energy on the damage factor (Fig. 8). Nevertheless, the effect of the proton energy is small or in an opposite way than expected, which is an unexpected behavior. We suspect that the use of shielding may generate errors in the fluence (dose enhancement from reflections or partial shadowing) and/or the energy spectrum (broadening and generation of secondary particles). This result will be considered in the interpretation of the data in the section $\mathrm{V}$.

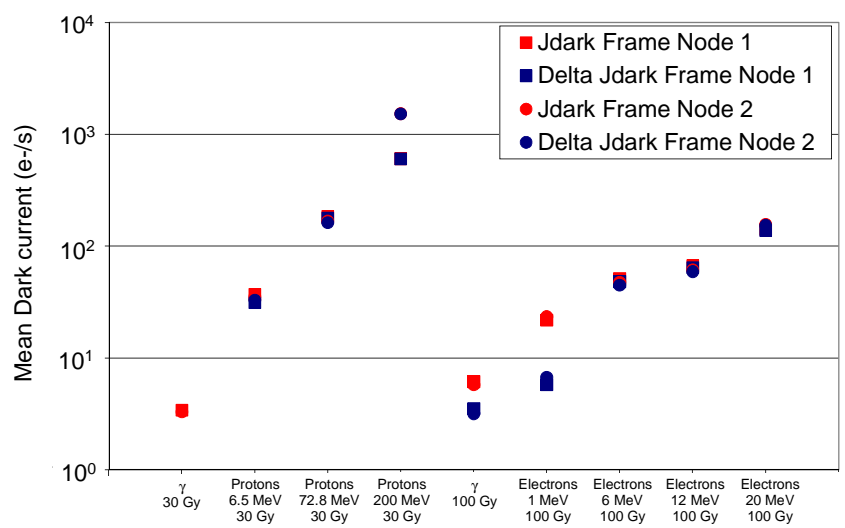

Fig. 7: CCD47-20 dark current and mean dark current increase after irradiation on the frame region nodes 1 and 2 at $-10^{\circ} \mathrm{C}$.

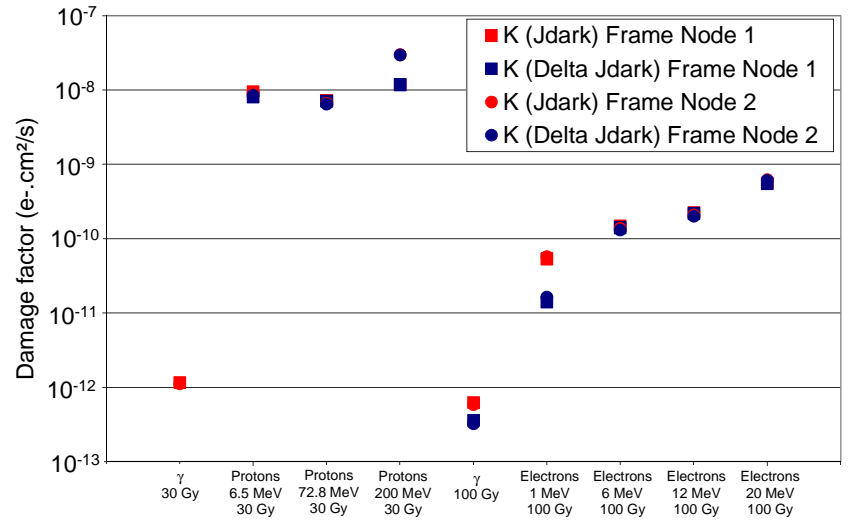

Fig. 8: CCD47-20 damage factor of the mean dark current and mean dark current increase after irradiation on the frame region nodes 1 and 2 at $-10^{\circ} \mathrm{C}$.

\section{Photodiode CANBERRA FD50-14-300RM}

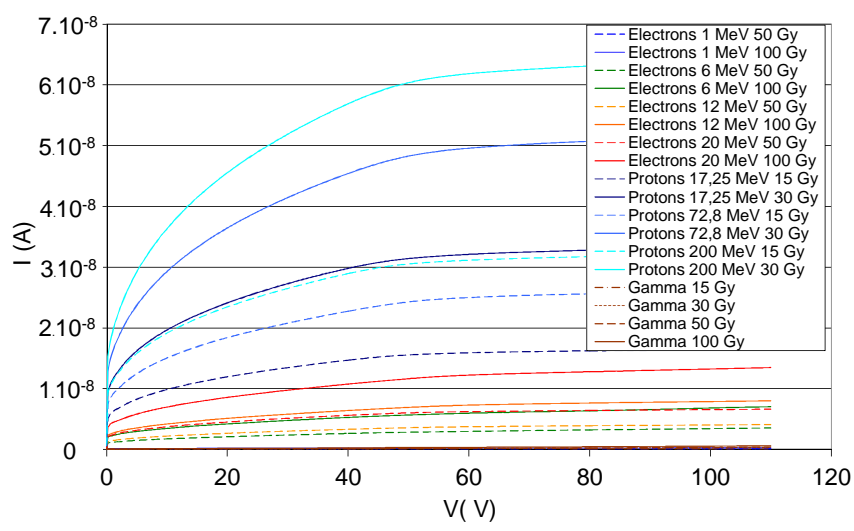

Fig. 9: $\mathrm{I}(\mathrm{V})$ of the reverse current increase of the PIPS photodiodes after irradiation at $27^{\circ} \mathrm{C}$.

Fig. 9 shows the $\mathrm{I}(\mathrm{V})$ curves of the CANBERRA photodiodes after irradiation. Because two samples are irradiated per energy and particle with two different fluences (see TABLE I), we can check that the increase of the dark 
current is proportional to the fluence. Fig. 10 gives the damage factor of the dark current. These devices are minimally sensitive to ionizing effects at $100 \mathrm{~Gy}(\mathrm{Si})$ and we can evaluate a displacement damage factor even for low energy electrons (see Fig. 11). This factor is stable as soon as the device is in full depletion mode whereas it decreases in a partially depleted mode. This factor is less accurate for gamma irradiation because the degradation is small. For the data interpretation, we will consider the value at the full depletion, i. e. close to 70-80 V.

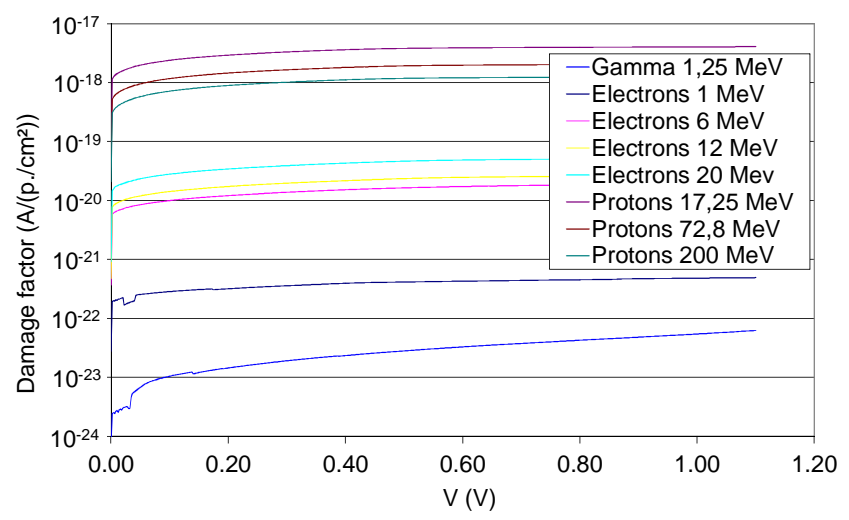

Fig. 10: Canberra PIPS diodes reverse dark current increase damage factor as a function of reverse bias at $27^{\circ} \mathrm{C}$.

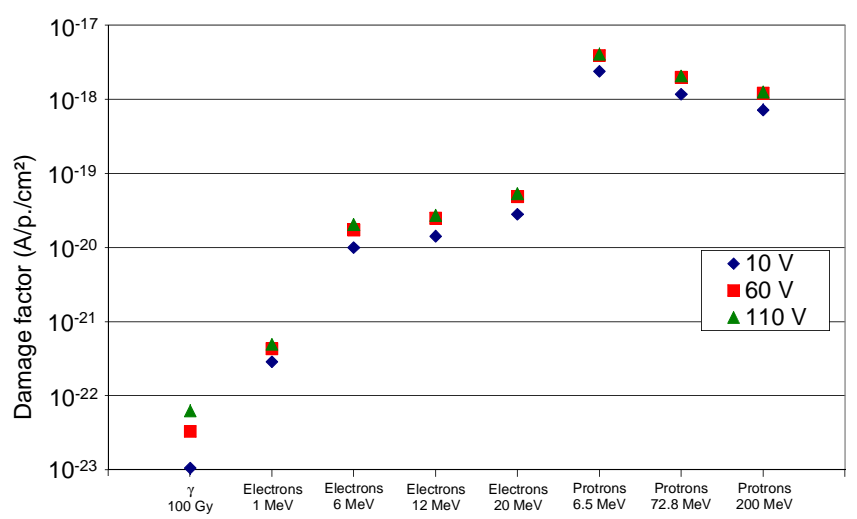

Fig. 11: Canberra PIPS diodes reverse dark current increase damage factor as a function of reverse bias at $27^{\circ} \mathrm{C}$.

\section{D. $I_{s c}$ on Hamamatsu and CANBERRA photodiodes}

Finally, Fig. 12 shows the $\mathrm{I}_{\mathrm{sc}}$ damage factor normalized to $800 \mathrm{keV}$ (a common energy for the two devices). These data are quite consistent with one another.

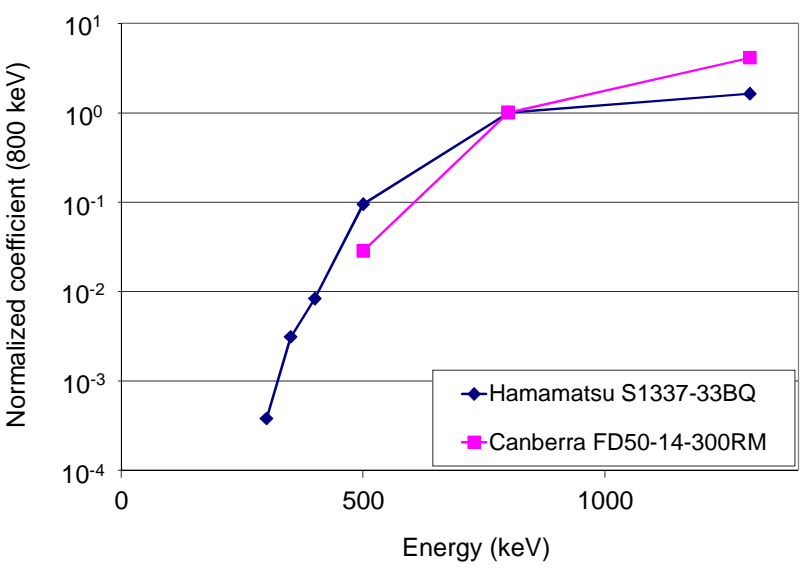

Fig. 12: $\mathrm{I}_{\mathrm{sc}}$ damage factor for the Canberra PIPS diodes and the Hamamatsu photodiodes normalized to $800 \mathrm{keV}$.

\section{DISCUSSION}

From the previous results, we can compare the different damage factors with the calculated NIEL. Such a comparison can only be done at this stage thanks to a normalization of the damage factors with a NIEL value. Indeed, the devices have different sensitive volumes and may be measured at different temperatures and different parameters are involved (dark current generation and diffusion length). The absolute values of damage factors are thus different. Usually low energy protons are chosen $(\sim 10 \mathrm{MeV}$ protons $)$ as the normalization value, because the NIEL of such protons, driven by the coulombic scattering, is expected to be known with a good accuracy. In addition scattering of experimental data obtained with low energy protons is expected to be lower than for electrons and high energy protons for which usually larger deviations are observed. For the results dealing with the diffusion length, because only electron irradiations were done, the damage factor have been normalised at $1.3 \mathrm{MeV}$ electrons because it is the highest common energy value available for the two different photodiodes.

In Fig. 13, the normalisation of the imagers and photodiode results is made with the lowest proton energy NIEL, $(6.5 \mathrm{MeV}$ for the CCD and the CIS, 17.25 MeV for the photodiodes). There is a consistent behaviour between CIS and PIPS dark current data for proton energies, and between the dark current PIPS and the $\mathrm{I}_{\mathrm{sc}}$ damage factor for electron irradiations. On the other side, the CIS dark current damage factor for electrons is much higher than the other data and the NIEL values. This is clearly due to the overestimation of this damage factor due to the high sensitivity of this device to the total ionizing dose at $100 \mathrm{~Gy}(\mathrm{Si})$, as presented in paragraph IV.A. This confirms that the CIS electron damage factor cannot be taken into account in this discussion. Nevertheless, the dark current damage factors of the CCD come apart from the other data. We can clearly see that the proton results of the CCD are not consistent with the expected trends. As presented in the paragraph IV.B, the use of a shielding during the irradiation may have induced some unexpected effects of energy broadening and particle scattering. Moreover, the CCD dark current damage factors for the electron irradiations are one 
decade over the dark current PIPS and $I_{\mathrm{sc}}$ results. This later point may be as a consequence of the low proton energy normalisation. Indeed, if the normalisation value is subject to errors, all the data are shifted.

In Fig. 14, the data are normalized to $6.5 \mathrm{MeV}$ protons for CIS, $17.25 \mathrm{MeV}$ protons for photodiodes and $20 \mathrm{MeV}$ electrons for the CCD. The CCD data are therefore normalized with the highest electron energy, chosen because of the convergence of the effective and classical NIEL at this energy. Fig. 14 reveals the inconsistent proton CCD and electron CIS data. The other results, both the dark current and $\mathrm{I}_{\mathrm{sc}}$ damage factors, are consistent with one another and suggest that the "effective" NIEL relationship holds better for electron displacement damage than the "classical" NIEL, in term of the shape of the curve and the ratio between electron and proton NIEL (and damage factor). They also strengthen the fact that the ionizing dose effect on the dark current is negligible for CCD and PIPS after the electron irradiations.

Finally, the dark current damage factors for the gamma irradiations are compared to the gamma NIEL calculations in Fig. 13 and Fig. 14. Considering only the normalization proposed in Fig. 14 because of the previous discussion, we see that the gamma experimental results are between the gamma NIEL and effective NIEL calculations, but closer to the classical NIEL than the effective one. As the other results show that the degradation induced by the electrons follows the "effective" NIEL, the case of ${ }^{60} \mathrm{Co}$ gamma rays should have been in agreement with the ${ }^{60} \mathrm{Co}$ NIEL calculated with the "effective" NIEL of electrons. But it is clearly not the case. This behaviour could be understood only if a significant ratio of ionizing dose effect (compared to displacement damage effects) takes place during gamma irradiation. Indeed, the irradiations are made with the same total ionizing dose, but the NIEL drops significantly for gamma irradiation. Moreover, as previously mentioned (paragraph IV.A), the yield is not the same between gamma and electron irradiations (neither the dose rate), which should enhance the total dose effects during gamma irradiations. At first order one can imagine that for ${ }^{60}$ Co gamma rays the TID effect and the DDD effect are in the same order of magnitude.

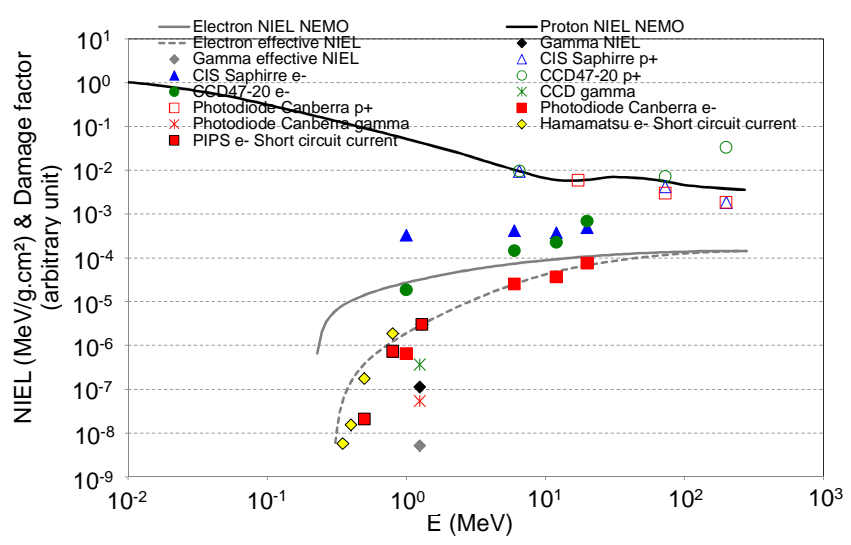

Fig. 13: Comparison data vs. NIEL and "effective" NIEL. Dark current data normalized at 6.5 or $17.25 \mathrm{MeV}$ protons. $\mathrm{I}_{\mathrm{sc}}$ data normalized at $1.3 \mathrm{MeV}$ electrons.

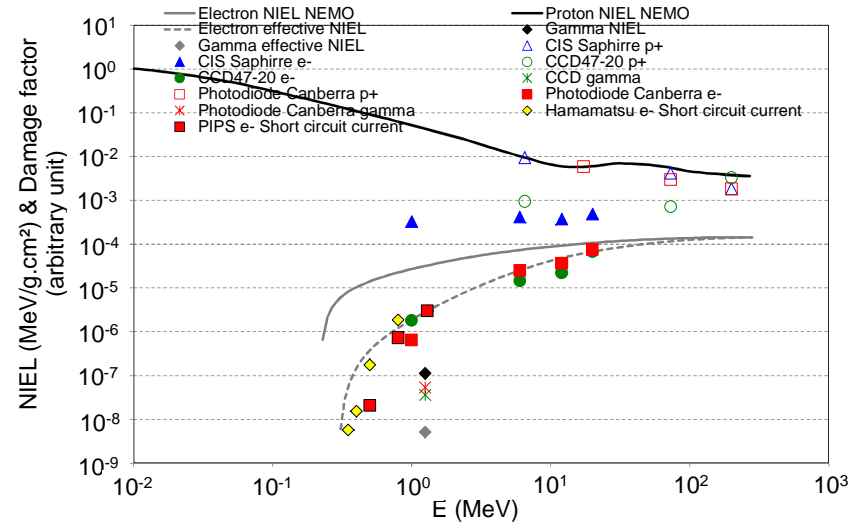

Fig. 14: Comparison data vs. NIEL and "effective" NIEL. Dark current data normalized at $6.5 \mathrm{MeV}$ protons for CIS, $17.25 \mathrm{MeV}$ protons for photodiodes and $20 \mathrm{MeV}$ electrons for $\mathrm{CCD}$. $\mathrm{I}_{\mathrm{sc}}$ data normalized at $1.3 \mathrm{MeV}$ electrons.

\section{CONCLUSION}

The experimental results of displacement damage factors are better described by an effective NIEL relationship than the classical NIEL model for electron irradiations. Some additional gamma NIEL calculations are proposed assuming two methods and compared with previous works. The results are much lower than the ones presented in [16] and are consistent with the ones in [22]. The gamma experimental data are in between the two NIEL calculation methods. Because the gamma NIEL calculation is based on the electron NIEL and the experimental damage factors fit with the effective NIEL for electron, this could be explained if there is a non-negligible total ionizing dose effect for gamma irradiations.

\section{REFERENCES}

[1] S. R. Messenger et al., "Non ionizing energy loss (NIEL) for heavy ions," IEEE Trans. Nucl. Sci., vol. NS-46, no. 6, pp. 1595-1602, Dec. 1999.

[2] A. Akkerman et al. "Updated NIEL calculations for estimating the damage induced by particles and gamma-rays in Si and GaAs," Rad. Phys. and Chem., vol. 62, pp. 301-310, 2001.

[3] I. Jun, W. Kim, and R. Evans, "Electron nonionizing energy loss for device applications," IEEE Trans. Nucl. Sci., vol. NS-56, no. 6, pp. 3229-3235, Dec. 2009.

[4] C. Inguimbert, and R. Gigante, "NEMO: A code to compute NIEL of protons, neutrons, electrons, and heavy ions," IEEE Trans. Nucl. Sci., vol. NS-53, no. 4, pp. 1967-1972, Aug. 2006.

[5] M. J. Boschini et al., "Nuclear and non-ionizing energy-loss for Coulomb scattered particle from low energy up to relativistic regime in space radiation environment," in Proc. the 12th ICATPP Conference on Astroparticle, Particle, Space Physics and Detectors for Physics Applications, Como, Italy, pp. 9-23, Oct. 2010.

[6] J. R. Srour, "Review of displacement damage effects in silicon devices," IEEE Trans. Nucl. Sci., vol. NS-50, no. 3, pp. 653-670, Jun. 2003.

[7] M. A. Xapsos et al., "Co60 Gamma Ray and Electron Displacement Damage Studies of Semiconductors," IEEE Trans. Nucl. Sci., vol. NS41, no. 6, pp. 1945-1949, Dec. 1994.

[8] J. R. Srour, J. W. Palko " A framework for understanding displacement damage mechanisms in irradiated silicon devices," IEEE Trans. Nucl. Sci., vol. NS-53, no. 6, pp. 3610-3620 Dec. 2006

[9] G. P. Summerset al., "Correlation of Particle-Induced Displacement Damage in Silicon," IEEE Trans. Nucl. Sci., vol. NS-34, no. 6, pp. 1133-1139, Dec. 1987.

[10] S. R. Messenger et al., "Modeling solar cell degradation in space: A comparison of the NRL displacement damage dose and JPL equivalent fluence approaches," Progress in Photovoltaics: Research and Applications, vol. 9, pp. 103-121, 2001. 
[11] K. Thommen, "Recovery of low temperature electron irradiationinduced damage in n-type GaAS," Radiation effects, vol. 2, no. 3, pp. 201-210, 1970 .

[12] A. H. Kalma, R. A. Berger, C. J. Fischer, and B. A. Green, "Energy and temperature dependence of electron irradiation damage in GaAs," IEEE Trans. Nucl. Sci., vol. NS-22, no. 6, pp. 2277-2282, Dec. 1975.

[13] D. Pons, P. M. Mooney, and J. C. Bourgoin, "Energy-dependence of deep level introduction in electron-irradiated GaAs," J. Applied Phys., vol. 51, no. 6, pp. 2038-2042, Apr. 1980

[14] M. Yamaguchi, C. Amano, " ${ }^{" 60} \mathrm{Co} \square$-ray and electron irradiation damage of GaAs single crystals and solar cells," J. Applied Phys., vol. 54, no. 9 , pp. 5021-5029, Sep. 1983.

[15] A. Meulenberg et al., "Dosimetry and total dose radiation testing of GaAs devices," IEEE Trans. Nucl. Sci., vol. NS-34, no. 6, pp. 17451750, Dec. 1987.

[16] G. P. Summers et al., "Damage correlations in semiconductors exposed to gamma, electron and proton radiations," IEEE Trans. Nucl. Sci., vol. NS-40, no. 6, pp. 1372-1379, Dec. 1993.

[17] G. P. Summers, E. A. Burke, and M. A. Xapsos, "displacement damage analogs to ionizing radiation effects," Rad. Meas., vol. 24, no. 1, pp. 1$8,1995$.

[18] J. H. Warner et al., "Correlation of electron radiation induced damage in GaAs solar cells,” IEEE Trans. Nucl. Sci., vol. NS-53, no. 4, pp. 1988 1994, Aug. 2006.

[19] J. H. Warner et al., " A comparison between $p+n$ and $n+p$ GaAs displacement damage coefficients following proton irradiation, " $33 \mathrm{rd}$ IEEE Photovoltaic Specialists Conference, pp. 1-5, 2008.

[20] P. Arnolda, C. Inguimbert, T. Nuns, C. Boatella-Polo, " NIEL scaling: comparison with measured defect introduction rate in silicon," IEEE Trans. Nucl. Sci., vol. NS-58, no. 3, pp. 756-763, Jun. 2011.

[21] E. EL Allam, C. Inguimbert, T. Nuns, A. Meulemberg, A. Jorio, I. Zorkani, " Gamma and Electron NIEL Dependence of Irradiated GaAs," IEEE Trans. Nucl. Sci., vol. NS-64, no. 3, pp. 991-998, Mar. 2017.

[22] M. El Allam, C. Inguimbert, T. Nuns, A. Meulenberg, A. Jorio, I. Zorkani, "Gamma non-ionizing energy loss: Comparison with the damage factor in silicon devices," J. of Appl. Phys. Vol. 123, p. 095703 2018.

[23] A. M. Ougouag, J.G. Williams, M. B. Danjaji, J. L. Yang, J. L. Meason, "Differential displacement kerma cross sections for neutron interactions in Si and GaAs," IEEE Trans. Nucl. Sci., vol. NS-37, no. 6, Part II, pp. 2219-2228, Dec. 1990.

[24] C. Inguimbert, P. Arnolda, T. Nuns, and G. Rolland, "Effective NIEL in silicon: Calculation using molecular dynamic results," IEEE Trans. Nucl. Sci., vol. NS-57, no. 4, pp. 1915-1923, Dec. 2010.

[25] C. Inguimbert, and S. Messenger, "Equivalent displacement damage dose for on-orbit space application," IEEE Trans. Nucl. Sci., vol. NS-59, no. 6, pp. 3117-3125, Dec. 2012.

[26] M. El Allam, C. Inguimbert, T. Nuns, A. Meulenberg, A. Jorio, I. Zorkani, "Gamma and Electron NIEL Dependence of Irradiated GaAs" IEEE Trans. Nucl. Sci., vol. NS-64, no. 3, pp. 991-998, March 2017.

[27] M. El Allam, C. Inguimbert, A. Meulenberg, A. Jorio, I. Zorkani, "Gamma non-ionizing energy loss: Comparison with the damage factor in silicon devices," J. of Appl. Phys., vol. 123, pp. 095703-1-095703-5, 2018 .

[28] J.R. Janesick, "Scientific Charge-coupled devices," Bellingham: SPIE press book, 2001

[29] J. J. Lofersky, P. Rappaport, "Radiation Damage in Ge and Si detected by carrier lifetime changes: Damage threshold," Phys. Rev., vol. 111 $\mathrm{n}^{\circ} 2,15$ July 1958 .

[30] S. R. Messenger, M. A. Xapsos, G. P. Summers, and E. A. Burke, “60 Co gamma ray irradiations of solar cells: A new way to predict space radiation damage," in Proc. IEEE 1st World Conf. Photovoltaic Energy conversion, vol. 2, pp. 2153-2156, 1994.

[31] S. R. Messenger, "Electron- and Gamma-Induced Displacement Damage Effects in InP Semiconductor Devices," PhD Dissertation, University of Maryland, 1995.

[32] J. R. Srour, "Universal damage factor for radiation-induced dark current in Silicon devices," IEEE Trans. Nucl. Sci., vol. NS-47, no 6, pp. 24512459, Dec. 2000. 